\title{
Distúrbios trombofilicos em crianças e adolescentes com trombose da veia porta
}

\author{
Thrombophilic disorders in children and adolescents with portal vein thrombosis
}

\author{
Raquel B. Pinto ${ }^{1}$, Themis R. Silveira ${ }^{2}$, Liane Rosling ${ }^{3}$, Eliane Bandinelli ${ }^{4}$
}

\section{Resumo}

Objetivo: determinar a freqüência de deficiência da proteína C (PC), proteína S (PS) e antitrombina (AT) e das mutações fator V Leiden (FVL), G20210A, no gene da protrombina (PTR), e C677T da metilenotetraidrofolato redutase (MTFR) em crianças e adolescentes com trombose da veia porta (TVP), e definir o padrão hereditário de uma eventual deficiência.

Métodos: durante o período de dois anos, foi investigada a presença de distúrbios trombofílicos em 14 crianças e adolescentes (grupo 1) com TVP, seus pais (grupo 2, n = 25) e dois grupos controles constituídos, o primeiro, por crianças e adolescentes sem hepatopatia, pareados por idade com as crianças do grupo $1(\mathrm{n}=28)$, e o outro, por pacientes com cirrose $(n=24)$. Os pacientes com TVP foram investigados do ponto de vista clínico, laboratorial, endoscópico e com biópsia de fígado. O diagnóstico da trombose foi realizado por ultra-sonografia abdominal com Doppler e/ou estudo angiográfico.

Resultados: a frequiência da deficiência de PC, PS e AT nos pacientes com TVP foi de $6 / 14(42,9 \%)(\mathrm{p}<0,05$ versus controles sem hepatopatia), $3 / 14(21,4 \%)(p>0,05)$ e $1 / 14(7,1 \%)$ ( $p>0,05)$, respectivamente. Nos pacientes com cirrose, a freqüência da deficiência de PC, PS e AT foi de $14 / 24(58,3 \%), 7 / 24(29,2 \%)$ e $11 / 24(45,8 \%)$, respectivamente ( $\mathrm{p}<0,05$ versus controles sem hepatopatia). A deficiência dessas proteínas não foi identificada nos pais dos pacientes com TVP e em nenhum controle sem hepatopatia. A mutação G20210A da PTR foi identificada em um paciente com TVP e em um controle sem hepatopatia $(\mathrm{p}=0,999)$. A mutação C677T da MTFR foi observada na forma homozigótica, em 3/14 (21,4\%) dos pacientes com TVP, e em 5/28 (17,9\%) controles $(\mathrm{p}=0,356)$. Em nenhum paciente ou controle sem hepatopatia foi identificado o FVL.

Conclusões: metade das crianças e adolescentes com TVP apresentou deficiência de uma ou mais proteínas inibidoras da coagulação, principalmente da proteína $\mathrm{C}$, mas esta deficiência não parece ser de origem genética. Os distúrbios trombofílicos hereditários não representaram papel importante como causa da TVP nas crianças e adolescentes. Nos pacientes cirróticos, houve maior freqüência de deficiência das proteínas na presença de doença de maior intensidade.

J Pediatr (Rio J) 2003;79(2):165-72: trombose da veia porta, hipertensão porta, proteínas inibidoras da coagulação, proteína C, proteína $\mathrm{S}$, antitrombina, fator $\mathrm{V}$ Leiden.

\begin{abstract}
Objective: to determine the frequency of protein C, protein S and antithrombin deficiency, and factor V Leiden, prothrombin G20210A, and methylenetetrahydrofolate reductase C677T mutations in children and adolescents with portal vein thrombosis, as well as assessing the hereditary character of this disorders.
\end{abstract}

Methods: a two-year study was carried out to determine the frequency of thrombophilic disorders in children and adolescents with portal vein thrombosis $(n=14)$, their parents $(n=24)$, and two control groups, one age-matched children and adolescents free of liver disease $(\mathrm{n}=28)$ and another group with cirrhosis $(n=24)$. The portal vein thrombosis patients were investigated by clinical and laboratory means, esophagogastroduodenal endoscopy and liver biopsies. The presence of portal vein thrombosis was assessed by Doppler ultrasonography and/or angiographic analysis.

Results: the frequency of protein $\mathrm{C}$, protein $\mathrm{S}$ and antithrombin deficiency was $6 / 14(42.9 \%)(p<0.05$ versus. controls), $3 / 14(21.4 \%)$ $(\mathrm{p}>0.05)$ and $1 / 14(7.1 \%)(\mathrm{p}>0.05)$ of children and adolescents with portal vein thrombosis, respectively. The frequency of protein $\mathrm{C}$, protein $\mathrm{S}$ and antithrombin deficiency in cirrhotic patients was 14/24 (58.3\%), $7 / 24(29.2 \%)$ and $11 / 24(45.8 \%)$, respectively ( $\mathrm{p}<0.05$ versus controls free of liver disease). None of the portal vein thrombosis parents or controls presented protein $\mathrm{C}$, protein $\mathrm{S}$ or antithrombin deficiency. One portal vein thrombosis patient and one control $(\mathrm{p}=0.999)$ presented prothrombin G20210A mutation. The homozygous form of methylenetetrahydrofolate reductase C677T mutation was observed in $3 / 14(21.4 \%)$ patients with portal vein thrombosis and in 5/28 (17.9\%) $(\mathrm{p}=0.356)$ controls. None of the patients or controls presented the factor V Leiden.

Conclusions: half of the children and adolescents with portal vein thrombosis presented deficiency of one or more coagulation inhibitor proteins, mainly protein $\mathrm{C}$, but this deficiency does not seem to be an inherited condition. The hereditary prothrombotic disorders do not seem to play a vital role in thrombosis in patients with portal vein thrombosis of this study. In the cirrhotic patients, there was a higher frequency of protein deficiency when the disease was more intense.

J Pediatr (Rio J) 2003;79(2):165-72: portal vein thrombosis, portal hypertension, coagulation inhibitor proteins, protein $\mathrm{C}$, protein $\mathrm{S}$, antithrombin, factor V Leiden.

1. Doutora em Gastroenterologia pela Universidade Federal do Rio Grande do Sul. Médica Pediatra com área de atuação em Gastroenterologia Pediátrica.

2. Doutora em Genética. Professora Adjunta de Pediatria da Universidade Federal do Rio Grande do Sul.

3. Mestre em Clínica Médica pela Universidade Federal do Rio Grande do Sul, Bióloga.

4. Doutora em Genética pela Universidade Federal do Rio Grande do Sul, Bióloga.

Este estudo foi premiado como o melhor trabalho clínico no X Congresso Brasileiro de Gastroenterologia Pediátrica, em maio de 2001, Brasília-DF. Fontes financiadoras: FIPE-HCPA, CAPES.

Artigo submetido em 14.10.02, aceito em 31.01.03. 


\section{Introdução}

Por definição, há hipertensão porta quando a pressão no sistema porta é superior a 10-12 mm Hg, ou 17-20 cm de água. $\mathrm{O}$ aumento na pressão porta é causado por condições que impedem o fluxo normal do sangue através deste sistema. Do ponto de vista anatômico, pode-se considerar três diferentes locais para a obstrução: pré-hepático, quando a obstrução ao fluxo venoso é causada por alterações estruturais da veia porta extra-hepática; intra-hepática, quando a resistência vascular é dentro do fígado; e suprahepática, se a obstrução venosa é localizada na saída do órgão. A trombose da veia porta (TVP) é uma das causas mais comuns de hipertensão porta na infância, sendo identificada em $40 \%$ de crianças com hemorragia digestiva devido a varizes de esôfago ${ }^{1}$. A trombose porta, como entidade patológica isolada, foi por muito tempo considerada pouco comum, mas estudos recentes identificaram freqüências tão expressivas quanto 24/65 (37\%) e 23/37 $(62 \%)$ em pacientes de diversas idades ${ }^{2,3}$.

$\mathrm{Na}$ última década, ficou estabelecido o aumento do risco da trombose associada à deficiência hereditária das proteínas inibidoras da coagulação, proteínas $\mathrm{C}, \mathrm{S}$ e antitrombina, responsáveis pela trombose em menos de 5\% dos pacientes ${ }^{4}$. Mais recentemente, com o advento da técnica de biologia molecular, outros distúrbios trombofílicos foram identificados como importantes fatores de risco em pacientes com trombose venosa. As mutações no fator $\mathrm{V}$, conhecidas como fator V Leiden e G20210A do gene da protrombina, foram identificadas em $20 \%$ e $6 \%$ dos pacientes com trombose venosa, respectivamente ${ }^{5}$. O polimorfismo C677T da metileno-tetraidrofolato redutase, na forma homozigótica, também está associado à trombose venosa em alguns estudos ${ }^{6}$.

Em adultos com TVP, é descrita a associação com distúrbios trombofílicos, em $60 \%$ a $75 \%$ dos casos, e a fatores locais, em $40 \%^{7,8}$. Diferentemente dos adultos, o fator etiológico da trombose em crianças e adolescentes ainda não é identificado na maioria dos $\operatorname{casos}^{1}$. Costuma estar associado a intercorrências durante o período neonatal, tais como cateterismo umbilical, onfalite e/ou septicemia, e parece ser resultante de uma anomalia congênita em alguns casos ${ }^{9-11}$. A investigação dos distúrbios trombofílicos em pacientes pediátricos com TVP foi realizada apenas em um número limitado de estudos e, muito raramente, foram estudados os pais dessas crianças ${ }^{12-14}$.

O objetivo do presente estudo é avaliar a freqüência da deficiência de proteína $\mathrm{C}$ (PC), proteína $\mathrm{S}$ (PS) e antitrombina (AT) e a presença das mutações fator V Leiden (FVL), G20210A da protrombina (PTR) e C677T da metilenotetraidrofolato redutase (MTFR), em crianças e adolescentes com TVP, e investigar um eventual caráter hereditário da deficiência das proteínas inibidoras da coagulação nestes pacientes.

\section{Casuística e métodos}

Foi realizado um estudo transversal durante um período de dois anos (junho de 1997 a junho de 1999), no Hospital de Clínicas de Porto Alegre. Foram estudados quatro grupos de indivíduos. O primeiro grupo foi composto por 14 crianças e adolescentes com TVP, e o grupo 2, pelos pais dessas crianças. Os grupos 3 e 4 constituíram os controles, o grupo 3 foi formado por 28 crianças sem hepatopatia, pareados por idade com os integrantes do grupo 1, e o grupo 4 , por 24 crianças e adolescentes com cirrose. Os pacientes com cirrose foram divididos em dois subgrupos, de acordo com a intensidade da doença, pela classificação de Child$\mathrm{Pugh}^{15}$. O primeiro subgrupo foi constituído pelas crianças e adolescentes com cirrose de leve intensidade (Child-Pugh A), e o segundo, pelos pacientes com cirrose de intensidade moderada (Child-Pugh B) ou grave (Child-Pugh C). O estudo foi aprovado pelo Comitê de Ética do hospital, tendo sido obtido consentimento informado por escrito dos responsáveis pelas crianças e adolescentes incluídos no estudo.

Os pacientes com TVP foram avaliados sob ponto de vista clínico e laboratorial, tendo sido dada ênfase especial à pesquisa de fatores de risco para trombose (cateterismo umbilical, onfalite, septicemia e malformações congênitas). O diagnóstico da trombose foi realizado por ultrasonografia abdominal com Doppler e/ou fase venosa do angiograma celíaco seletivo. Endoscopia digestiva alta foi realizada em todos os pacientes. Os pacientes do grupo 1 apresentaram transaminases, bilirrubinas, fosfatase alcalina e gama-glutamiltransferase normais e marcadores sorológicos para hepatite $\mathrm{B}$ e $\mathrm{C}$ negativos. Em 7/14 pacientes, foram realizadas biópsias hepáticas, que não apresentaram alterações.

A dosagem da atividade das proteínas $\mathrm{C}$, S e antitrombina foi realizada em todos os indivíduos. A presença das mutações FVL, G20210A da PTR e C677T da MTFR foi avaliada nos pacientes com TVP (grupo 1), nos pais das crianças que apresentaram a mutação (grupo 2) e nos controles sem hepatopatia (grupo 3). A presença das mutações não foi investigada nos pacientes com cirrose (grupo 4).

\section{Coleta de sangue}

Para realização dos exames, foram misturadas 9 partes da amostra com 1 parte de citrato de sódio a 3,8\% em tubos de vidro siliconizado. $\mathrm{O}$ sangue foi então centrifugado por 15 minutos a $2.500 \mathrm{~g}$. O plasma foi separado em pequenas alíquotas, colocado em tubos plásticos, identificado e armazenado a $-80{ }^{\circ} \mathrm{C}$.

\section{Análises específicas}

A dosagem quantitativa das proteínas $\mathrm{Ce} \mathrm{S}$ foi realizada pelo método coagulométrico, utilizando-se o kit STACLOT Protein $C$, Diagnóstica $\mathrm{Stago}^{16}$. Para dosagem da atividade da proteína $\mathrm{S}$, foi utilizado o kit STACLOT Protein $S$, Diagnóstica Stago ${ }^{17}$. A atividade da antitrombina foi medida pelo teste colorimétrico, utilizando-se o kit STACHROM AT III, Diagnóstica Stago ${ }^{18}$. Os valores 
foram interpolados em uma curva de calibração, e os resultados expressos em porcentagem, de um plasma de referência. Os valores de referência para a atividade das proteínas foram obtidos através da subtração de dois desvios padrão da média da atividade das proteínas dos controles sem hepatopatia. Os valores de referências utilizados foram $51 \%, 53 \%$ e $76 \%$ para proteína C, S e antitrombina, respectivamente.

\section{Análise genética}

O DNA de alto peso molecular dos leucócitos foi extraído do sangue periférico pelos métodos padrões ${ }^{19}$. A mutação fator $\mathrm{V}$ Leiden foi detectada pela amplificação do éxon 10 do gene do fator $\mathrm{V}$, através da reação de polimerase em cadeia (PCR), seguida por clivagem pela enzima de restrição $M n l{ }^{20}$. A identificação da mutação G20210A na região não traduzida do gene da protrombina foi realizada pela técnica de PCR, seguida de clivagem pela enzima de restrição HindIII ${ }^{21}$. A mutação C677T da metileno-tetraidrofolato redutase foi detectada por amplificação por PCR, seguida por clivagem pela enzima de restrição HinfI ${ }^{22}$.

\section{Análise estatística}

Na comparação das variáveis categóricas, adotou-se o teste de $\chi^{2}$ e exato de Fisher, quando necessário. Adicionalmente, foi efetuado o ajuste dos múltiplos valores $\mathrm{p}$, obtidos mediante o procedimento proposto por $\mathrm{Hommel}^{23}$. O nível de significância utilizado foi de $\alpha=0,05$. Os dados foram analisados com auxílio dos programas Epi-Info V6 and Pepi V3.

\section{Resultados \\ Característica da amostra (Tabela 1)}

Os pacientes com TVP eram caucasóides e apresentavam uma média e desvio padrão de idade de 8 anos e 8 meses \pm 4 anos e 5 meses (amplitude de 1 ano e 9 meses a 17 anos e 2 meses) e, do diagnóstico, de 3 anos e 8 meses \pm 3 anos e 6 meses (amplitude de 3 meses a 10 anos). Metade dos pacientes pertenciam ao gênero masculino. Os motivos principais de investigação da TVP foram hemorragia digestiva em 9/14 e esplenomegalia em 5/14 pacientes. Anomalias congênitas extra-hepáticas foram identificadas em 3/14 pacientes (válvula aórtica bicúspide (caso 1), estenose da transição pelviureteral com hidronefrose secundária (caso $5)$ e persistência do canal arterial (caso 10). Dois pacientes eram portadores da síndrome de Turner (casos 1 e 5). Fatores de risco para TVP foram identificados em 5/14 pacientes, cateterismo em três, onfalite em um, e septicemia em um. Nenhum paciente tinha história familiar de consangüinidade ou trombose venosa.

O grupo controle sem hepatopatia (grupo 3) foi composto por crianças e adolescentes sem queixas relacionadas ao fígado e vias biliares, selecionadas no Ambulatório de Pediatria do HCPA. A média de idade do grupo controle sem hepatopatia foi de 8 anos e 10 meses \pm 4 anos e 5 meses.

Tabela 1 - Características de 14 crianças e adolescentes com trombose da veia porta

\begin{tabular}{|c|c|c|c|c|c|c|}
\hline Caso & Gênero & $\begin{array}{l}\text { Grupo } \\
\text { racial }\end{array}$ & $\begin{array}{l}\text { Idade por ocasião } \\
\text { do diagnóstico } \\
\text { (anos e meses) }\end{array}$ & $\begin{array}{l}\text { Idade por ocasião } \\
\text { do início do estudo } \\
\text { (anos e meses) }\end{array}$ & $\begin{array}{l}\text { Circunstância } \\
\text { do diagnóstico }\end{array}$ & $\begin{array}{l}\text { Fatores } \\
\text { de risco }\end{array}$ \\
\hline 1 & $\mathrm{~F}$ & $\mathrm{C}$ & $1 \mathrm{a} 3 \mathrm{~m}$ & $4 a$ & HDA & Malformação \\
\hline 2 & M & $\mathrm{C}$ & $6 \mathrm{a} 1 \mathrm{~m}$ & $7 \mathrm{a} 1 \mathrm{~m}$ & $\mathrm{E}$ & Onfalite \\
\hline 3 & M & $\mathrm{C}$ & $8 \mathrm{a} 11 \mathrm{~m}$ & $12 \mathrm{a} 1 \mathrm{~m}$ & HDA & Cateterismo \\
\hline 4 & $\mathrm{~F}$ & $\mathrm{C}$ & $8 \mathrm{~m}$ & $9 \mathrm{a} 11 \mathrm{~m}$ & $\mathrm{E}$ & - \\
\hline 5 & $\mathrm{~F}$ & $\mathrm{C}$ & $2 \mathrm{a} 6 \mathrm{~m}$ & $4 \mathrm{a} 5 \mathrm{~m}$ & HDA & Malformação \\
\hline 6 & $\mathrm{~F}$ & $\mathrm{C}$ & $8 a$ & $11 \mathrm{a} 8 \mathrm{~m}$ & HDA & Cateterismo \\
\hline 7 & M & $\mathrm{C}$ & $3 \mathrm{~m}$ & $5 \mathrm{a} 10 \mathrm{~m}$ & $\mathrm{E}$ & Septicemia \\
\hline 8 & F & $\mathrm{C}$ & $1 \mathrm{a} 3 \mathrm{~m}$ & $3 a$ & HDA & - \\
\hline 9 & M & $\mathrm{C}$ & $10 \mathrm{a}$ & $12 \mathrm{a} 4 \mathrm{~m}$ & HDA & - \\
\hline 10 & $\mathrm{~F}$ & $\mathrm{C}$ & $1 \mathrm{a} 6 \mathrm{~m}$ & $17 \mathrm{a} 2 \mathrm{~m}$ & HDA & Malformação \\
\hline 11 & $\mathrm{~F}$ & $\mathrm{C}$ & $1 \mathrm{a} 9 \mathrm{~m}$ & $1 \mathrm{a} 9 \mathrm{~m}$ & $\mathrm{E}$ & - \\
\hline 12 & M & $\mathrm{C}$ & $6 \mathrm{a} 11 \mathrm{~m}$ & $8 \mathrm{a} 8 \mathrm{~m}$ & HDA & $\begin{array}{l}\text { Cateterismo } \\
\text { Malformação }\end{array}$ \\
\hline 13 & M & $\mathrm{C}$ & $2 \mathrm{a} 4 \mathrm{~m}$ & $12 \mathrm{a} 9 \mathrm{~m}$ & HDA & - \\
\hline 14 & M & $\mathrm{C}$ & $4 \mathrm{~m}$ & $10 \mathrm{a} 5 \mathrm{~m}$ & $\mathrm{E}$ & - \\
\hline
\end{tabular}

F: feminino, M: masculino, C: caucasóide, HDA: hemorragia digestiva alta, E: esplenomegalia. 
O grupo 4 foi formado por pacientes com cirrose, comprovada por biópsia hepática, atendidos no mesmo ambulatório. A média de idade do grupo controle com cirrose foi de 8 anos e 6 meses \pm 5 anos e 2 meses. $O$ fator etiológico da cirrose foi atresia das vias biliares extrahepática $(n=10)$, hepatite auto-imune $(n=3)$, vírus $B(n=1)$ e vírus $C(n=1)$. Em 9/24 pacientes não foi identificada a causa da cirrose. Metade das crianças com cirrose foram classificadas como Child-Pugh A (12/24), 10/24 pertenciam ao grupo Child-Pugh B e 2/24 ao grupo Child-Pugh C.

\section{Distúrbios trombofilicos (Tabela 2)}

Proteínas inibidoras da coagulação

Metade das crianças e adolescentes com TVP apresentou deficiência de uma ou mais proteínas inibidoras da coagulação. Deficiência da proteína $\mathrm{C}$ foi observada em $6 / 14$ pacientes ( $p<0,05$ versus controles sem hepatopatia), da proteína $\mathrm{S}$, em $3 / 14$ ( $\mathrm{p}=0,190$ versus controles), e da antitrombina, em $1 / 14$ ( $\mathrm{p}=0,580$ versus controles). Deficiência isolada de uma proteína inibidora da coagulação foi observada em 4 pacientes (casos 3, 5, 9, 13) e de mais de uma proteína em 3 casos (casos 1, 8 e 12).

Os pais das crianças com TVP (grupo 2) e os controles sem hepatopatia (grupo 3) não apresentaram deficiência das proteínas inibidoras da coagulação.
Em 16/24 (66,7\%) crianças com cirrose, verificou-se diminuição da atividade de uma ou mais proteínas inibidoras da coagulação. Redução da proteína $C$ foi observada em $14 / 24(58,3 \%)$, da proteína S em 7/24 (29,2\%), e da antitrombina em $11(45,8 \%)(\mathrm{p}<0,05$ versus controles sem hepatopatia). No grupo de crianças com cirrose de intensidade leve (Child-Pugh A), a redução da atividade da proteína $\mathrm{C}$ foi observada em 3/12 (25\%), da proteína $\mathrm{S}$ em $2 / 12$ $(16,7 \%)$ e da antitrombina, em $2 / 12(16,7 \%)$ ( $p>0,05$ versus controles). Todas as crianças com cirrose Child-Pugh B e C apresentaram deficiência de uma ou mais proteínas inibidoras da coagulação. Neste subgrupo, a deficiência de proteína C foi observada em 11/12 (91,7\%), da proteína $\mathrm{S}$, em 5/12 $(41,7 \%)$, e da antitrombina, em 9/12 (75\%) ( $<<0,05$ versus controles).

\section{Análise genética}

A mutação FVL não foi identificada em nenhum paciente ou controle. A mutação G20210A da PTR (Figura 1) foi observada em um paciente e em um controle sem hepatopatia $(p=0,999)$. Esta mutação também foi identificada no pai do paciente com TVP portador da mutação. A forma homozigótica da mutação C677T da MTFR (Figura 2) foi constatada em 3/14 (21\%) pacientes com TVP, e em 5/28 (18\%) controles $(\mathrm{p}=0,356)$.

Tabela 2 - Atividade da proteína C, proteína S e antitrombina, presença das mutações fator V Leiden, G20210A da protrombina e C677T da metileno-tetraidrofolato redutase em 14 crianças e adolescentes com trombose da veia porta

\begin{tabular}{lcccccc}
\hline Paciente & $\begin{array}{c}\text { Atividade das proteínas inibidoras da coagulação } \\
\text { Proteína S }(\%) \\
\text { Antitrombina }(\%) \\
\text { (normal }>\text { 53\%) }\end{array}$ & $\begin{array}{c}\text { FVL } \\
\text { (normal> 54\%) }\end{array}$ & $\begin{array}{c}\text { Mutações } \\
\text { G20210 } \\
\text { da PTR }\end{array}$ & $\begin{array}{c}\text { C677T } \\
\text { da MTFR }\end{array}$ \\
\hline 1 & $44^{*}$ & $39^{*}$ & 83 & GG & GG & TT \\
2 & 90 & 158 & 111 & GG & GG & CC \\
3 & $47^{*}$ & 81 & 89 & GG & GG & TT \\
4 & 65 & 60 & 87 & GG & GA & TC \\
5 & $46^{*}$ & 91 & 85 & GG & GG & TC \\
6 & 66 & 55 & 94 & GG & GG & TT \\
7 & 70 & 83 & 101 & GG & GG & CC \\
8 & $41^{*}$ & $46^{*}$ & 86 & GG & GG & TC \\
9 & $43^{*}$ & 101 & 103 & GG & GG & CC \\
10 & 77 & 120 & 93 & GG & GG & CC \\
11 & 78 & 90 & 80 & GG & GG & CC \\
12 & 55 & $50^{*}$ & $65^{*}$ & GG & GG & CC \\
13 & $33^{*}$ & 82 & 85 & GG & GG & CC \\
14 & 71 & 93 & 82 & GG & GG & CT \\
Média $( \pm D P)$ & $59 \pm 17.11$ & $82.07 \pm 31.90$ & $88.86 \pm 11.27$ & & & \\
Controles & $81,82 \pm 15,21$ & $95,46 \pm 21,02$ & $102,00 \pm 12,89$ & - & & \\
Média $( \pm D P)$ & & & & & & \\
\hline
\end{tabular}

FVL: Fator V Leiden, PTR: Protrombina, MTFR: metileno-tetraidrofolato redutase, GG e CC: homozigoto normal, GA: heterozigoto para a mutação G20210A da protrombina, TC e CT: heterozigoto para a mutação da metileno-tetraidrofolato redutase, TT: homozigoto para a mutação da MTFR, $*$ : valores alterados. 


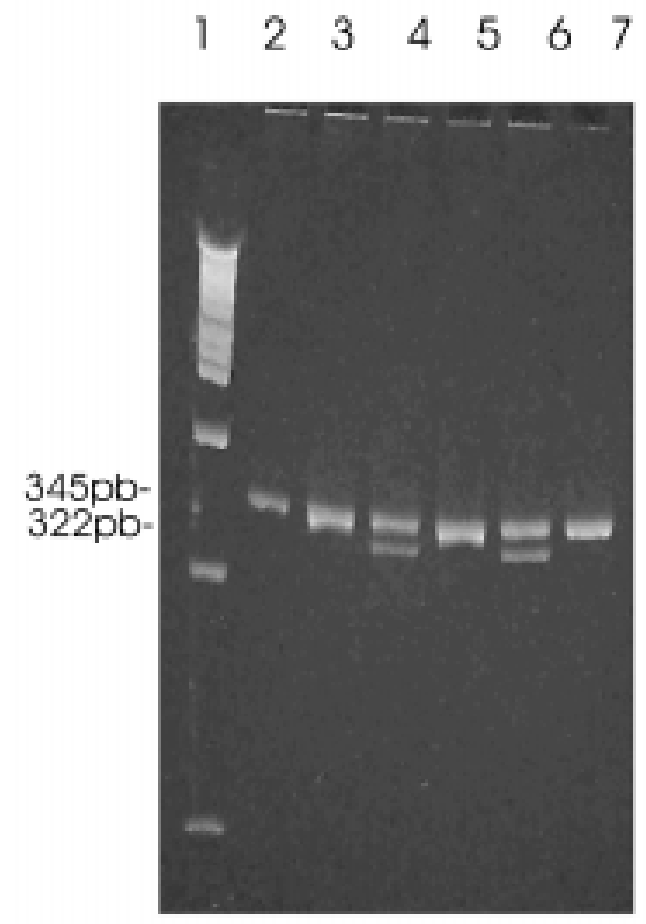

Figura 1 - Identificação da mutação da protrombina por PCR. (1): Marcador de peso molecular. $(2,3,4,5,6,7)$ : indivíduos analisados. $\mathrm{O}$ fragmento de DNA amplificado apresenta 345 pares de bases ( $\mathrm{pb}$ ). Na presença do alelo $\mathrm{G}$ (normal), o fragmento de $345 \mathrm{pb}$ permanece inalterado (indivíduos 2,3,5,7: homozigotos GG). Na presença do alelo A (mutante), esse fragmento é clivado pela enzima HindIII, resultando em fragmentos de $322 \mathrm{pbe}$ $23 \mathrm{pb}$ (indivíduos 4,6: heterozigotos GA)

\section{Discussão}

O presente estudo permitiu a identificação de um ou mais distúrbios trombofílicos em 9/14 (64\%) crianças e adolescentes com TVP. Apesar de que a metade das crianças investigadas apresentou deficiência de uma ou mais proteínas inibidoras da coagulação, a proteína que apresentou deficiência significativa em relação aos controles sem doença no fígado foi a proteína C. Esse fato pode estar relacionado à menor meia-vida da proteína $\mathrm{C}$ (6-8 horas) em relação a das outras proteínas, que é superior a $3 \operatorname{dias}^{24}$. A utilização de controles pareados por idade com as crianças e adolescentes com TVP foi necessária para a definição dos valores normais destas proteínas. Em pacientes pediátricos, os valores considerados normais diferem em relação aos dos adultos, devido a particularidades do sistema hemostático na infância ${ }^{25}$.

Com a complementação da investigação através da análise da atividade das proteínas nos pais destas crianças, não foi confirmado nenhum caso de deficiência hereditária, assim como na maioria dos pacientes pediátricos dos outros

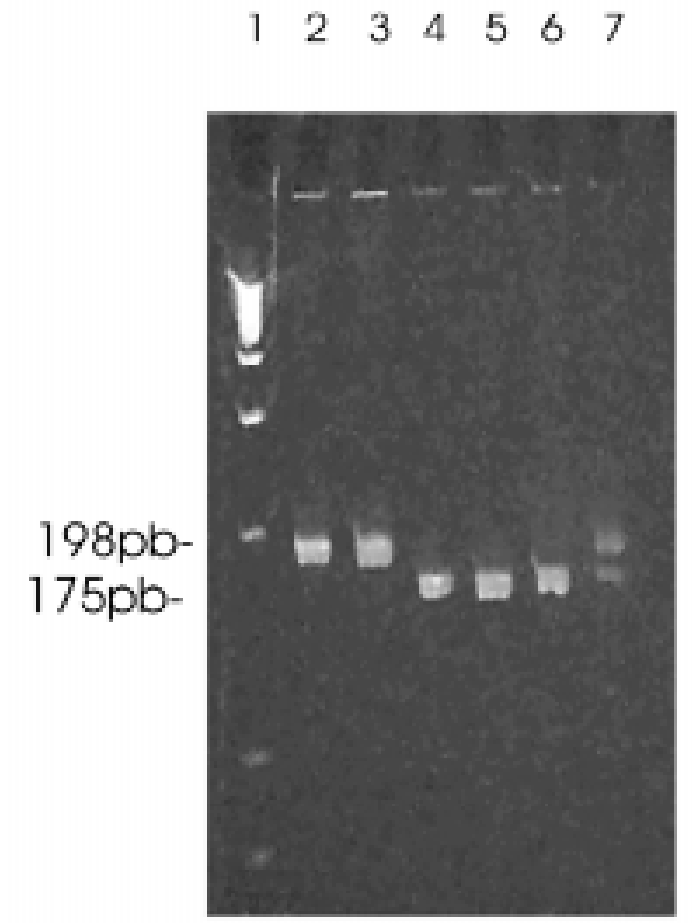

Figura 2 - Identificação da mutação C677T da metileno-tetraidrofolato redutase por PCR. (1): Marcador de peso molecular. $(2,3,4,5,6,7)$ : indivíduos analisados. O fragmento de DNA amplificado apresenta 198 pares de bases (pb). Na presença do alelo C (normal), o fragmento de DNA de 198pb permanece inalterado (indivíduos 2,3: homozigotos $\mathrm{CC}$ ). Na presença do alelo $\mathrm{T}$ (mutante), esse fragmento é clivado pela enzima HinfI, resultando em fragmentos de $175 \mathrm{pb}$ e $23 \mathrm{pb}$. Indivíduos 4,5,6: homozigotos TT. Indivíduo 7: heterozigoto

três estudos da literatura, nos quais foi realizada a investigação familiar (Tabela 3). Dubuisson et al. ${ }^{13}$ observaram apenas um caso com provável deficiência hereditária da proteína S; Uttenreuther-Fischer et al. ${ }^{3}$ registraram deficiência hereditária de proteína $\mathrm{C}$ em um paciente; e Heller et al. ${ }^{2}$ constataram deficiência genética de proteína $\mathrm{C}$ em um paciente e de antitrombina em outro. $\mathrm{O}$ resultado do nosso estudo, assim como o dos autores citados, indica que provavelmente a deficiência das proteínas inibidoras da coagulação, na maioria das crianças e adolescentes com TVP, é consequiência da trombose, e não a sua causa.

O mecanismo da deficiência (adquirida) das proteínas inibidoras da coagulação nos pacientes com TVP parece estar na dependência de um maior consumo relacionado à coagulação e à fibrinólise. Seria uma reação secundária à formação de derivações portossistêmicas decorrentes da hipertensão porta. Robson et al. ${ }^{26}$ sugerem que há ativação do sistema da coagulação relacionado à produção excessiva de trombina no cavernoma porta e/ou nas derivações portossistêmicas ${ }^{26}$. Fischer et al. ${ }^{27}$ também aventam a possibi- 
Tabela 3 - Freqüência dos distúrbios trombofílicos em crianças e adolescentes com trombose da veia porta, em estudos da literatura

\begin{tabular}{|c|c|c|c|c|c|c|}
\hline \multirow[b]{2}{*}{ Autores } & \multicolumn{3}{|c|}{ Deficiência das proteínas inibidoras da coagulação } & \multicolumn{3}{|c|}{ Mutações investigadas } \\
\hline & Proteína C & Proteína S & Antitrombina & FVL & $\begin{array}{l}\text { G20210A } \\
\text { da PTR }\end{array}$ & $\begin{array}{l}\text { C677T } \\
\text { da MTFR }\end{array}$ \\
\hline $\begin{array}{l}\text { Dubuisson et al., } \\
1997(\mathrm{n}=20)\end{array}$ & $\begin{array}{l}\text { a) } 9(45 \%) \\
\text { b) } 0 \%\end{array}$ & $\begin{array}{l}\text { a) } 13(55 \%) \\
\text { b) } 1(10 \%)\end{array}$ & $\begin{array}{l}\text { a) } 10(50 \%) \\
\text { b) } 0 \%\end{array}$ & NR & NR & NR \\
\hline $\begin{array}{l}\text { Uttenreuther-Fischer } \\
\text { et al., } 1997(n=23)\end{array}$ & $\begin{array}{l}\text { a) }- \\
\text { b) } 1(4 \%)\end{array}$ & $\begin{array}{l}\text { a) }- \\
\text { b) } 0 \%\end{array}$ & $\begin{array}{l}\text { a) }- \\
\text { b) } 0 \%\end{array}$ & $2(9 \%)$ & NR & NR \\
\hline $\begin{array}{l}\text { Heller et al., } 2000 \\
(\mathrm{n}=24)\end{array}$ & $\begin{array}{l}\text { a) }- \\
\text { b) } 1(4 \%)\end{array}$ & $\begin{array}{l}\text { a) }- \\
\text { b) } 0 \%\end{array}$ & $\begin{array}{l}\text { a) }- \\
\text { b) } 1(4 \%)\end{array}$ & $4(17 \%)$ & $0 \%$ & $1(4 \%)$ \\
\hline $\begin{array}{l}\text { Este estudo } \\
(n=14)\end{array}$ & $\begin{array}{l}\text { a) } 6(43 \%) \\
\text { b) } 0 \%\end{array}$ & $\begin{array}{l}\text { a) } 3(21 \%) \\
\text { b) } 0 \%\end{array}$ & $\begin{array}{l}\text { a) } 1(7 \%) \\
\text { b) } 0 \%\end{array}$ & $0 \%$ & $1(7 \%)$ & $3(21 \%)$ \\
\hline
\end{tabular}

NR: Não realizado, a) freqüência da deficiência adquirida, b) freqüência da deficiência hereditária, FVL: fator V Leiden, PTR: protrombina, MTFR: metileno-tetraidrofolato redutase.

lidade de que, além da diminuição das proteínas, devido a um maior consumo, também poderia ocorrer uma síntese menor, decorrente da diminuição do fluxo sangüíneo hepático, ocasionando algum grau de atrofia hepática (Figura 3). A deficiência secundária das proteínas $\mathrm{C}, \mathrm{S}$ e antitrombina, provavelmente causada pela redução da síntese protéica hepática, fica bem evidente quando os resultados observados no grupo de pacientes com cirrose são analisados. Nestes pacientes, a redução dos valores protéicos foi mais nítida naqueles com doença mais grave.

Comparando a freqüência da deficiência hereditária das proteínas inibidoras da coagulação, observadas na Tabela 3, com a freqüência destes distúrbios na população geral e nos pacientes com trombose venosa, observamos que a freqüência da deficiência das proteínas inibidoras da coagulação nas crianças e adolescentes com TVPé comparável àquela encontrada na trombose venosa de outras localizações (Tabela 4).
Em relação às mutações investigadas no nosso estudo, o fator $\mathrm{V}$ Leiden, que parece ser um importante fator de risco pró-trombótico, responsável por trombose venosa espontânea na infância ${ }^{28}$, não foi identificado em nenhum dos pacientes estudados. Essa mutação também não foi observada em outros dois estudos pediátricos realizados no Brasil $^{12,14}$, sendo que, em um destes estudos, foram investigadas 49 crianças e adolescentes com TVP ${ }^{14}$. Resultados diferentes foram constatados em outros dois estudos realizados na Alemanha (Tabela 3), nos quais a mutação fator $\mathrm{V}$ Leiden foi identificada em $9 \%$ e $17 \%$ dos pacientes ${ }^{2,3}$.

Dentre os estudos que investigaram a presença da mutação G20210A da protrombina em crianças e adolescentes com TVP, o nosso estudo foi o único que identificou um paciente com esta mutação. Apesar de a freqüência desta mutação ser a mesma observada no grupo controle e comparável à da população geral (Tabela 4), o paciente portador da mutação G20210A da PTR (caso 4) não apresentava

Tabela 4 - Prevalência de distúrbios trombofílicos hereditários na população geral, em pacientes com trombose venosa e em crianças e adolescentes com trombose da veia porta (\%)

\begin{tabular}{|c|c|c|c|c|c|}
\hline \multirow[t]{2}{*}{ Prevalência } & \multicolumn{3}{|c|}{ Deficiência das proteínas inibidoras da coagulação } & \multicolumn{2}{|c|}{ Mutações } \\
\hline & PC $(\%)$ & PS $(\%)$ & $\mathrm{AT}(\%)$ & FVL $(\%)$ & $\operatorname{PTR}(\%)$ \\
\hline População geral* & $0,2-0,4$ & $\mathrm{NC}$ & 0,02 & 5 & 2 \\
\hline $\begin{array}{l}\text { Pacientes com } \\
\text { trombose venosa* }\end{array}$ & 3 & $1-2$ & 1 & 20 & 6 \\
\hline Crianças com TVP** & 2,5 & 1,2 & 1,2 & 9,8 & 2,6 \\
\hline
\end{tabular}




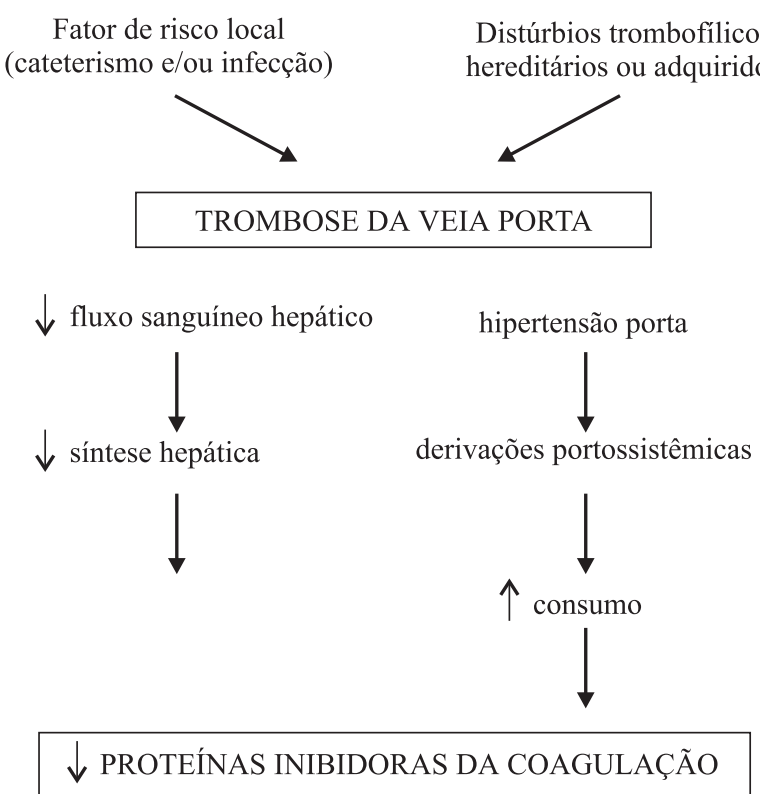

Figura 3 - Mecanismo proposto para a redução da atividade das proteínas inibidoras da coagulação em crianças e adolescentes com trombose da veia porta. (Fischer et al., 2000, modificado)

nenhum outro fator de risco genético ou adquirido identificado. Em um único estudo realizado em adultos com TVP, foi observado uma associação freqüente com o polimorfismo da PTR, identificado em 4/10 pacientes ${ }^{29}$.

A mutação C677T da enzima metileno-tetraidrofolato redutase, responsável pelo defeito enzimático mais comum associado à hiper-homocisteinemia, fator de risco conhecido para trombose arterial e, mais recentemente, investigada em pacientes com trombose venosa, também foi identificada nos pacientes com trombose, deste estudo, em proporção semelhante aos controles sem hepatopatia. Alguns autores associaram a presença desta mutação com trombose venosa, mas os resultados também são divergentes ${ }^{6,30}$.

Em síntese, os nossos resultados demonstram que a deficiência da proteína $C$ é freqüentemente encontrada nas crianças e adolescentes com TVP, mas não parece ser de origem genética. Possivelmente, a causa da deficiência das proteínas inibidoras da coagulação nesses pacientes seja secundária a um maior consumo decorrente da presença das derivações portossistêmicas na hipertensão porta. Outra possibilidade é a ocorrência de uma menor síntese, devido à redução do fluxo sangüíneo hepático ocasionado pela trombose. Portanto, os distúrbios trombofílicos, de natureza hereditária, não parecem apresentar um papel importante em relação à trombose nas crianças e adolescentes com TVP estudadas.

\section{Agradecimentos}

Agradecemos pelo auxílio recebido do FIPE (Fundo de Incentivo à Pesquisa e Eventos do Grupo de Pesquisa e PósGraduação do HCPA) e da CAPES (Coordenação de Aperfeiçoamento de Pessoal de Nível Superior).

Um especial agradecimento à Vânia Hirakata e ao Dr. Mário Wagner, pelo auxílio na análise estatística.

\section{Referências bibliográficas}

1. Shneider BL. Portal hypertension. In: Wyllie R, Hyams JS. Pediatric Gastrointestinal Disease: Pathophysiology, diagnosis and management. $2^{\mathrm{a}}$ ed. W.B. Saunders Company; 1999. p. 625.

2. Heller C, Schobess R, Kurnik K, Junker R, Günther G, Kreuz W, et al. Abdominal venous thrombosis in neonates and infants: role of prothrombotic risk factors - a multicentre case-control study. Br J Haematol 2000;11:534-9.

3. Uttenreuther-Fischer MM, Vetter B, Hellmann C, Otting U, Ziemer S, Hausdorf G, et al. Paediatric thrombo-embolism: the influence of non-genetic factors and the role of activated protein C resistance and protein C deficiency. Eur J Pediatr 1997;156: 277-81.

4. Ridker PM. Inherited risk factors for venous thromboembolism: implications in clinical practice. Clin Cornerstone 2002;4:18-30.

5. Rosendaal FR. Venous thrombosis: a multicausual disease. Lancet 1999;353:1167-73.

6. Arruda VR, Von Zuben PM, Chiaparini LC, Annichino-Bizacchi JM, Costa FF. The mutation Ala677®Val in the methylene tetrahydrofolate reductase gene: a risk factor for arterial disease and venous thrombosis. Thromb Haemost 1997;77:812-21.

7. Janssen HLA, Meinardi J, Vleggaar FP, van Uum SHM, Haagsma EB, van der Meer FJM, et al. Factor V Leiden mutation, prothrombin gene mutation and deficiencies in coagulation inhibitors associated with Budd-Chiari syndrome and portal vein thrombosis: results of a case-control study. Blood 2000;96:2364-8.

8. Denninger M-H, Chaït Y, Casadevall N, Hillaire S, Guillin M$\mathrm{C}$, Bezeaud A, et al. Cause of portal or hepatic venous thrombosis in adults: the role of multiple concurrent factors. Hepatology 2000;31:587-91.

9. Pinto RB, Silveira TR. Trombose da veia porta em crianças e adolescentes: série de 14 casos. Rev AMRIGS 2002;46:47-52.

10. Odièvre M, Pigé G, Alagille D. Congenital abnormalities associated with extrahepatic portal hypertension. Arch Dis Child 1977;52:383-5.

11. Alvarez F, Bernard O, Brunelle F, Hadchouel P, Odiévre M, Alagille, D. Portal obstruction in children. I. Clinical investigation and hemorrhage risk. J Pediatr 1983;103:696-702.

12. Seixas CA, Hessel G, Ribeiro CC, Arruda VR, AnnichinoBizzacchi JM. Factor V Leiden is not common in children with portal vein thrombosis. Thromb Haemost 1997;77:258-61.

13. Dubuisson C, Boyer-Neumann C, Wolf M, Meyer D, Bernard O. Protein C, protein S and antithrombin III in children with portal vein obstruction. J Hepatol 1997;27:132-5.

14. Pugliese RPS, Porta G, D’Amico EA, Miura IK, Bydlowski S, Rocha TRF, et al. Fatores de risco em crianças e adolescentes portadores de trombose da veia porta e hipertensão portal. GED 1999;18 Supl 1:27.

15. Pugh RN, Murray-Lyon IM, Dawson JL, Pietroni MC, Williams R. Transection of the oesophagus for bleeding varices. Brit $\mathbf{J}$ Surg 1973;60:646-9. 
16. Martinoli JL, Stocker K. Fast functional protein C assay using Protac, a novel protein C activator. Thromb Res 1986;43:253-64.

17. Wolf M, Boyer-Neumann C, Martinoli J-L, Leroy-Matheron C, Amiral J, Meyer D, et al. A new functional assay for human protein $\mathrm{S}$ activity using factor $\mathrm{V}$ as substrate. Thromb Haemost 1989;62:1144-5.

18. Tollefson DM. Laboratory diagnosis of antithrombin and heparin cofactor II deficiency. Semin Thromb Haemost 1990;16:162-8.

19. Lahiri DK, Nurnberger JRI. A rapid non-enzymatic method for the preparation of HMW DNA from blood for RFLP studies. Nucleic Acids Res 1991;19:5444.

20. Bertina RM, Koeleman BPC, Koster T, Rosendaal FR, Dirven $\mathrm{RJ}$, Honde $\mathrm{H}$, et al. Mutation in blood coagulation factor $\mathrm{V}$ associated with resistance to protein C. Nature 1994;359:64-7.

21. Poort SR, Rosendaal FR, Reitsma PH, Bertina RM. A common genetic variation in the 3'-untranslated region of the prothrombin gene is associated with elevated plasma prothrombin levels and an increase in venous thrombosis. Blood 1996;88:3698-703.

22. Frosst P, Blom HJ, Milos R, Goyette P, Sheppard CA, Matthews $\mathrm{RG}$, et al. Candidate genetic risk factor for vascular disease: a common mutation in methylenetetrahydrofolate reductase. Nat Genet 1995;10:111-3.

23. Hommel GA. Stagewise rejective multiple test procedure based on a modified Bonferroni test. Biometrics 1988;75:383-6.

24. Dumontier I, Alhenc-Gelas M, Chatellier G, Brenet P. Modifications des taux des inhibiteurs plasmatiques de la coagulation au cours de la cirrhose. Étude prospective chez 33 malades. Gastroenterol Clin Biol 1992;16:120-5.

25. Andrew M, Vegh P, Johnsonton M, Browker J, Ofosu F, Mitchell L. Maturation of the hemostatic system during childhood. Blood 1992;80:1998-2005.
26. Robson SC, Kahn D, Kruskal J, Bird AR, Kirsch RE. Disordered hemostasis in extrahepatic portal hypertension. Hepatology 1993;18:853-6.

27. Fischer NC, Wilde JT, Roper J, Elias E. Deficiency of natural anticoagulant proteins $\mathrm{C}, \mathrm{S}$, and antithrombin in portal vein thrombosis: a secondary phenomenon? Gut 2000;46:534-9.

28. Schobess R, Junker R, Auberger K, Munchow N, Burdach S, Nowak-Gottl, U. Factor V G1691A and prothrombin G20210A in childhood spontaneous venous thrombosis - Evidence of an age-dependent thrombotic onset in carriers on factor V G1691A and prothrombin G20210A mutation. Eur J Pediatr 1999;158 Suppl 3:105-108.

29. Chamouard P, Pencreach E, Maloisel F, Grunebum L, ArdizzonE J-F, Meyer A, et al. Frequent factor II G20210A mutation in idiopathic portal vein thrombosis. Gastroenterology 1999;116:144-8.

30. Kosch A, Junker R, Kurnik K, Schobess R, Günther G, Koch H$\mathrm{G}$, et al. Prothrombotic risk factors in children with spontaneous venous thrombosis and their asymptomatic parents: a family study. Thromb Res 2000;531-7.

\section{Endereço para correspondência:}

Dra. Themis Reverbel da Silveira

Rua 24 de Outubro, 1181 - Auxiliadora

CEP 90510-003 - Porto Alegre, RS

Fone/fax: (51) 3342.5380

E-mail: tsilveira@hcpa.ufrgs.br 